\title{
The Effect of Light on the Developmental Cycle of Nostoc muscorum, a Filamentous Blue-Green Alga
}

\author{
BY N. LAZAROFF* AND W. VISHNIAC \\ Department of Microbiology, Yale University, New Haven, Connecticut, U.S.A.
}

(Received 1 December 1960)

\section{SUMMARY}

The Allison strain of Nostoc muscorum, when cultivated in complete darkness, differs morphologically from the forms which prevail in the light. When cultivated in the dark with glucose as energy and carbon source, the alga grows very slowly as a mass of large undifferentiated cells (the aseriate stage). Exposure to small amounts of light or the addition of aqueous extracts of light-grown cells enables development of typical nostocacean filaments. The aseriate morphology is a transient stage of development found in all autotrophic or photoheterotrophic cultures. By growing Nostoc in complete darkness and then exposing to light of low intensity, synchronous development occurs. The cyclic sequence of development is described. The inhibition of growth in the dark is interpreted as a lack of morphogenetic substances formed only in the light.

\section{INTRODUCTION}

Early investigators of the Hormogonales observed that many of these filamentous blue-green algae, collected from natural sources, displayed differentiated cells of two types: akinetes (gonidia) and heterocysts (De Bary, 1863; Janczewski, 1874; Bornet \& Thuret, 1880; Brand, 1903). Certain filaments or portions of filaments (trichomes) exhibited specialized structure or function. These filaments, if motile, were termed hormogonia, if non-motile, hormospores (hormocysts) (Thuret, 1844; Borzi, 1879; Bornet \& Flahault, 1886; Borzi, 1916). In addition, many of these organisms were found in nature to occur as macro colonies of characteristic morphology. The filamentous elements of each colony were, at times, arranged in a regular fashion (Bornet \& Thoret, 1880; Geitler, 1925; Fremy, 1930).

Evidently, a description of the life history of the filamentous blue-green algae must account for the formation of specialized cells and filaments. Nevertheless, a sequence of events explaining the formation and function of the specialized elements of the cyanophycean thallus has never been established. Instead, there arose the concept that development of the filamentous blue-green algae was a simple vegetative process analogous to reproduction of the true bacteria. This notion has been supported by the apparent cytological similarity of cyanophycean and bacterial cells, as well as by the recognition that the filamentous bacteria classified as Beggiatoaceae may be colourless relatives of Hormogonales, notwithstanding the dubious relationship of the Beggiatoaceae to the true bacteria (Pringsheim, 1949).

* Present address: Department of Biology, Brandeis University, Waltham, Massachusetts, U.S.A. 
Although pure cultures of the filamentous blue-green algae have been available for at least 40 years, little attention has been paid to the developmental morphology of these organisms (Pringsheim, 1913, 1946). The most notable pure culture studies were performed by Harder (1917a), who clearly showed that the production and subsequent growth of hormogonia were a means of new colony formation. These observations were in substantial agreement with those of Thuret (1844), Sauvageau (1897) and Geitler (1921) who studied similar phenomena in nature or in crude cultures.

Although the formation and germination of akinetes have been described by many investigators (Fritsch, 1904, 1945), the function and development of the heterocyst has not been elucidated despite the keen interest of phycologists in this enigmatic structure (Fritsch, 1951). Except for the observations of Harder (1917 $b$ ) and Fogg (1949), the effects of chemical or physical agents upon the development of the structures of the blue-green algal thallus have been neglected.

Allison, Hoover \& Morris (1937) described a strain of Nostoc muscorum capable of growth in the dark with either glucose or sucrose. In the present investigation, such heterotrophic cultures were found to differ morphologically from cultures grown in the light. Dark-grown cultures resembled old light-grown cultures of this organism as reported by Allison et al. (1937) and the stage of hormogone 'germination' described by Thuret (1844) and Sauvageau (1897). However, the morphology characteristic of the dark-grown alga could always be found as a transient but recurrent phase in cultures actively growing in the light. These observations suggested, and our experiments confirmed, that in the light a sequence of developmental stages occurred which was not completed during the slow but sustained growth which prevailed in the dark. The slow growth of the algae in the dark may be related to their inability to complete a developmental cycle under these conditions.

\section{METHODS}

The organism used in these studies was a strain of Nostoc muscorum kindly supplied by Dr F. E. Allison several years ago (designated Nostoc muscorum A).

The following two basal media were used: Medium 1 (modification of the medium described by Fogg (1942) for the cultivation of Anabaena cylindrica): $\mathrm{K}_{2} \mathrm{HPO}_{4}$, $0 \cdot 15$ g.; $\mathrm{MgSO}_{4} .7 \mathrm{H}_{2} \mathrm{O}, 0.20 \mathrm{~g}$; $\mathrm{CaCl}_{2} .2 \mathrm{H}_{2} \mathrm{O}, 0.025 \mathrm{~g}$; $\mathrm{FeCl}_{3} .6 \mathrm{H}_{2} \mathrm{O}, 2.0 \mathrm{mg}$.; $\mathrm{MnCl}_{2} .4 \mathrm{H}_{2} \mathrm{O}, 0.4 \mathrm{mg}$; $\mathrm{Na}_{2} \mathrm{MoO}_{4}, 0.4 \mathrm{mg}$.; $\mathrm{H}_{3} \mathrm{BO}_{3}, 0.6 \mathrm{mg}$.; $\mathrm{CuSO}_{4} .5 \mathrm{H}_{2} \mathrm{O}, 0.04 \mathrm{mg}$.; $\mathrm{ZnSO}_{4} \cdot 7 \mathrm{H}_{2} \mathrm{O}$, 0.04 mg.; distilled water to 11 . Medium 2 (a chelated solution): $\mathrm{K}_{2} \mathrm{HPO}_{4}, 0.15$ g.; $\mathrm{MgSO}_{4} .7 \mathrm{H}_{2} \mathrm{O}, 0.20$ g.; $\mathrm{CaCl}_{2} .2 \mathrm{H}_{2} \mathrm{O}, 0.025$ g.; disodium ethylenediamine tetraacetate, $0.05 \mathrm{~g}$.; $\mathrm{FeSO}_{4} .7 \mathrm{H}_{2} \mathrm{O}, 8.0 \mathrm{mg}$; $\mathrm{ZnCl}_{2}, 10.0 \mathrm{mg}$.; $\mathrm{H}_{3} \mathrm{BO}_{3}$, $1.0 \mathrm{mg}$.; $\mathrm{MnSO}_{4} \cdot 4 \mathrm{H}_{2} \mathrm{O}, 8.0 \mathrm{mg}$.; $\mathrm{CuCl}_{2} .2 \mathrm{H}_{2} \mathrm{O}, 1.0 \mathrm{mg}$; $\mathrm{CoCl}_{2} \cdot 6 \mathrm{H}_{2} \mathrm{O}, 1.0 \mathrm{mg}$.; $\mathrm{Na}_{2} \mathrm{SiO}_{3}, 0.025$ g.; $\mathrm{Na}_{2} \mathrm{MoO}_{4}, 3.0 \mathrm{mg}$.; distilled water to one litre.

In both these media, the first three salts were made up, as individual stock solutions. The other constituents were combined in a single stock solution made up at $\times 100$ the concentration desired in the final medium, and adjusted to $\mathrm{pH} \mathrm{4-5}$ with $\mathbf{H C l}$. Both media were adjusted to $\mathrm{pH} 7 \cdot 2$ before autoclaving.

Substances added to the basal media were sterilized separately by autoclaving, or by filtration through a Seitz or sintered-glass filter, and were added aseptically to the culture vessels. Liquid cultures were maintained in Pyrex culture tubes or 
$50 \mathrm{ml}$. Erlenmeyer flasks, each containing $10 \mathrm{ml}$. basal medium. In experiments with solid media, $1.5 \%(\mathrm{w} / \mathrm{v})$ agar was added to the nutrient solution before autoclaving. Any separately sterilized materials were added, after sterilization, to the cooled but still liquid agar. After mixing, about $12 \mathrm{ml}$. molten medium were poured into sterile Petri dishes and inoculated by spreading suspensions of algal material on the surface with sterile bent glass rods. Inoculum suspensions were routinely prepared by homogenizing the harvested alga for 30 sec. in a sterile Waring Blendor cup with a small amount of sterile basal medium. The suspensions were washed by sedimentation in a centrifuge and resuspended in sterile basal medium two or three times. The developmental morphology of Nostoc muscorum A was examined in cultures grown in light or darkness, on solid or liquid media, at a temperature of $\mathbf{2 4} \pm \mathbf{2}^{\circ}$. Cultures were illuminated with fluorescent lights and screened with layers of cheesecloth until the desired intensity, as measured by a Weston light meter with daylight filter, was obtained. Dark cultures were incubated in specially constructed light-tight boxes.

Photomicrographs were taken with a 'box camera' on Kodak Panatomic X film, through a Spencer research microscope.

\section{RESULTS}

When Nostoc muscorum A was cultivated in the light on the surface of solid inorganic media, the following phases of development were observed (PI. 1, figs. 1-8): motile trichome stage, aseriate stage, stage of rapid filament growth, dissolution of slimy envelope with consequent loosening of tightly packed filaments, and breaking of filaments at heterocysts to yield motile trichomes (hormogonia). The term aseriate stage is proposed for that phase of development in which the cells occur in packets and display no linear attachment to one another in continuous chains. During this study, it remained a moot point whether or not the cells within the packets were attached. Subsequently, it has been possible to show that the aseriate packets consist of groups of single cells or short chains, up to 3 or 4 cells in length, confined within a common sheath. The anastomoses of these cells to form continuous filaments will be described in a future paper. The hormogonia migrated freely over the surface of the agar in moving streams of filaments. They were often seen to aggregate in revolving spiral formations. Such filaments came to rest, and cell divisions took place in a plane parallel to the axis of the filament. Succeeding cell divisions produced clusters of cells (the aseriate stage) from each of the cells of the original hormogone, except that the terminal cells developed into terminal heterocysts. At the aseriate stage the large cells in each cluster did not immediately show a linear relationship to each other. However, upon subsequent development filamentation of the clumped cells occurred with the differentiation of intercalary heterocysts in the rapidly elongating new filaments. Breakage of filaments at the intercalary heterocysts liberated heterocysts and hormogonia.

The morphology characteristic of the organism grown for 2-4 weeks in a liquid inorganic medium at a light intensity of $200 \mathrm{ft}$.-candles is shown in Pl. 2, fig. 9. When the inorganic basal medium was supplemented with $1 \%(\mathrm{w} / \mathrm{v})$ sucrose or glucose very slow growth occurred in complete darkness. The morphology exhibited by the alga after growth for several weeks in the dark is shown in Pl. 2, figs. 10-12. 
The relationship between light intensity and dry weight of alga produced was examined in the following manner. Cardboard boxes, with cellophan windows on their under sides, were fitted with light-tight lids. The boxes were painted on the outside with aluminium paint, and on the inside surfaces with 'flat black'. The boxes were placed on glass shelves illuminated from below by a bank of fluorescent lights. By interposing various thicknesses of cheesecloth between the glass shelf and the cellophan windows of the boxes, any desired light intensity could be obtained. Culture tubes containing $10 \mathrm{ml}$. of chelated medium 2, with or without $1 \%(\mathrm{w} / \mathrm{v})$ separately sterilized glucose were arranged in the boxes in such manner as to receive the light coming from below. Nine boxes of this type were set up for observing growth under light intensities ranging from 1.0 to $450 \mathrm{ft}$.-candles. Similar culture tubes were inoculated simultaneously and incubated in complete darkness. The inoculum consisted of a loopful of a homogenized suspension prepared from a culture grown with agitation for 2 weeks on inorganic medium at a light intensity of $250 \mathrm{ft}$.-candles. After incubation for 22 days, the experimental cultures were harvested by centrifugation. After washing the organism twice with distilled water, pooled replicates were transferred to tared weighing bottles, and dried to constant weight in a forced-draft oven at $67^{\circ}$.

\section{Table 1. Growth as a function of light intensity and presence of glucose}

Each tube contained $10 \mathrm{ml}$. of Medium 2. Cultures were incubated for 22 days at $24 \pm 2^{\circ}$. Dry weights were obtained by pooling the contents of four replicate tubes, washing the algal contents, and drying to constant weight in tared weighing bottles.

\begin{tabular}{|c|c|c|}
\hline \multirow[b]{2}{*}{$\begin{array}{c}\text { Light intensity } \\
\text { (ft.-candles) }\end{array}$} & \multicolumn{2}{|c|}{ mg. dry weight of algal growth/tube } \\
\hline & Medium 2 & $\begin{array}{c}\text { Medium } 2 \\
+1 \% \text { glucose }\end{array}$ \\
\hline $\mathbf{0}$ & No growth & $\begin{array}{l}\text { Visible growth, } \\
\text { not weighable }\end{array}$ \\
\hline $1 \cdot 0$ & No growth & $\begin{array}{l}\text { Visible growth, } \\
\text { not weighable }\end{array}$ \\
\hline 4.5 & No growth & 1.2 \\
\hline 22 & $\begin{array}{l}\text { Visible growth, } \\
\text { not weighable }\end{array}$ & $\mathbf{3 \cdot 8}$ \\
\hline 45 & $1 \cdot 1$ & $6 \cdot 7$ \\
\hline 80 & 1.4 & $15 \cdot 8$ \\
\hline 160 & $\mathbf{3} \cdot \mathbf{1}$ & $6 \cdot 1$ \\
\hline 200 & $\mathbf{3} \cdot \mathbf{1}$ & $10 \cdot 8$ \\
\hline 290 & $4 \cdot 8$ & $12 \cdot 7$ \\
\hline 450 & $4 \cdot 3$ & $5 \cdot 8$ \\
\hline
\end{tabular}

Dry weights of algal material grown in tube cultures after incubation in darkness and at various light intensities are given in Table 1 . Light intensities which were insufficient for growth under photoautotrophic conditions produced a measurable growth response in tubes containing glucose. Growth was thus stimulated by glucose when photosynthesis was limited solely by low light intensity. Apparently light stimulated the use of glucose for growth. The quantity of growth which occurred in complete darkness was insufficient for dry weight measurement.

Figure 1 illustrates the development of cultures grown at different light intensities in media containing glucose. It may be noted that the morphological stages of development, described above, were correlated with growth which took place 
between 0 and $80 \mathrm{ft}$.-candles light intensity. This is the range at which light intensity is nearly proportional to growth response. Above $\mathbf{8 0} \mathrm{ft}$.-candles, growth decreased sharply, then resumed as the light intensity increased still further. From $80 \mathrm{ft}$.candles all tubes showed long filaments with intercalary heterocysts. Motile trichomes were not being formed and therefore the morphological stages associated with their further development were absent.

The response of Nostoc muscorum A to different light intensities suggests that cultures which have grown in complete darkness for extended periods might be inhibited in their development, either by the lack of essential substances formed only in the light, or by the accumulation in the dark of inhibitory material. When darkgrown cultures, exhibiting the aseriate morphology shown in Pl. 2, fig. 11, were

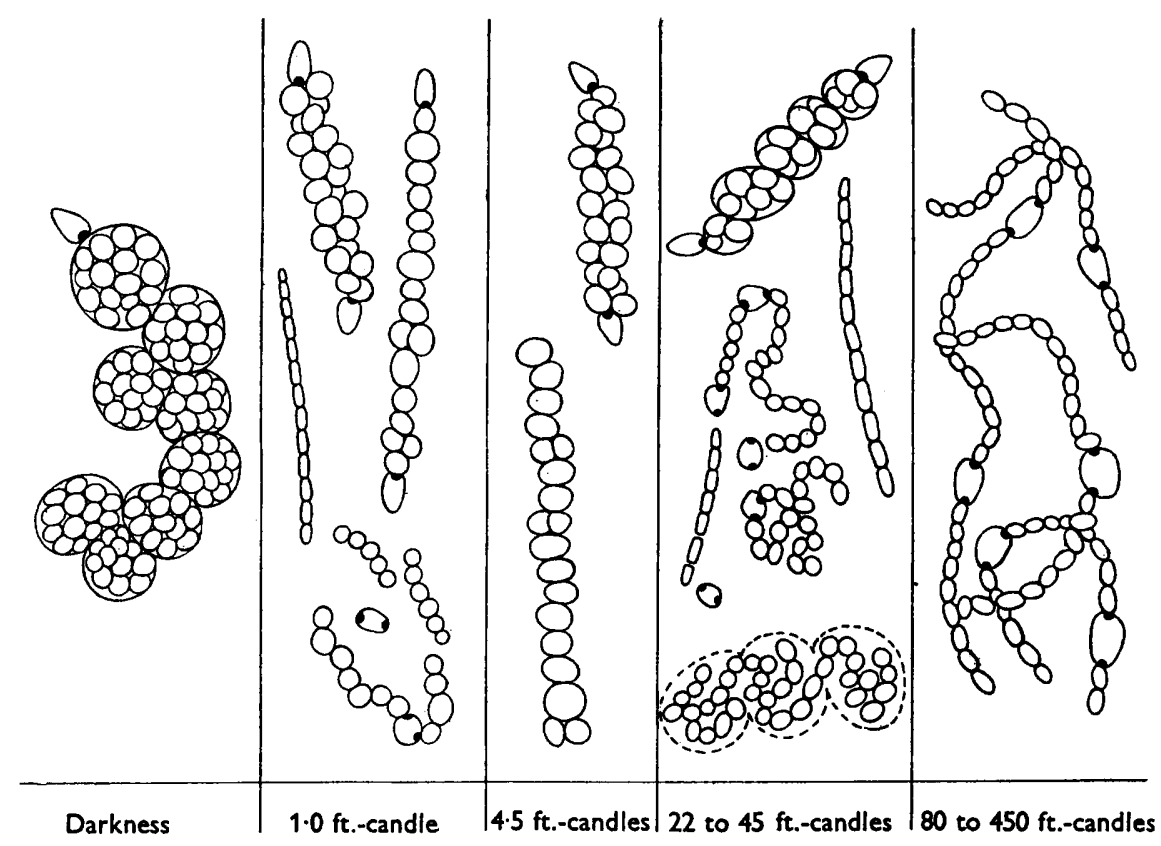

Fig. 1. Morphology of Nostoc muscorum A after 22 days in medium 2+1\% glucose at different light intensities.

placed in light of $50 \mathrm{ft}$.-candles intensity, rapid growth took place with a synchronized development of filaments similar to growth observed on solid media. Plates 2 and 3 show the developmental stages found in synchronous cultures. Figure 2 presents an over-all scheme of the developmental cycle of Nostoc muscorum $A$ deduced from those observations.

In accordance with the results obtained by Allison et al. (1937), only glucose, sucrose and fructose were found to support the growth of this organism in the dark. The following compounds and mixtures were ineffective as sole carbon sources in the dark: cellobiose, maltose, lactose, glycerol, pyruvate, succinate, citrate, lactate, acetate, urea, extract of Nostoc muscorum A, yeast extract, beef extract, malt extract, soil extract, plankton extract, casein hydrolysate, peptone, tryptone, nutrient broth, trypticase-soy broth, either alone or in combination or when sup- 
plemented with $\mathrm{NH}_{4} \mathrm{Cl}$ or $\mathrm{KNO}_{3}$. Growth in the dark on medium $2+1 \%$ glucose or sucrose was not stimulated by additional glucose or sucrose, or, with one exception, by the substances listed above. An extract of light-grown Nostoc muscorum $\mathrm{A}$, when added to medium $2+1 \%$ glucose or sucrose, markedly enhanced growth in the dark. The extract was prepared from algae grown with agitation in medium 2 at $250 \mathrm{ft}$.-candles. About $50 \mathrm{~g}$. wet weight of algal material was ground

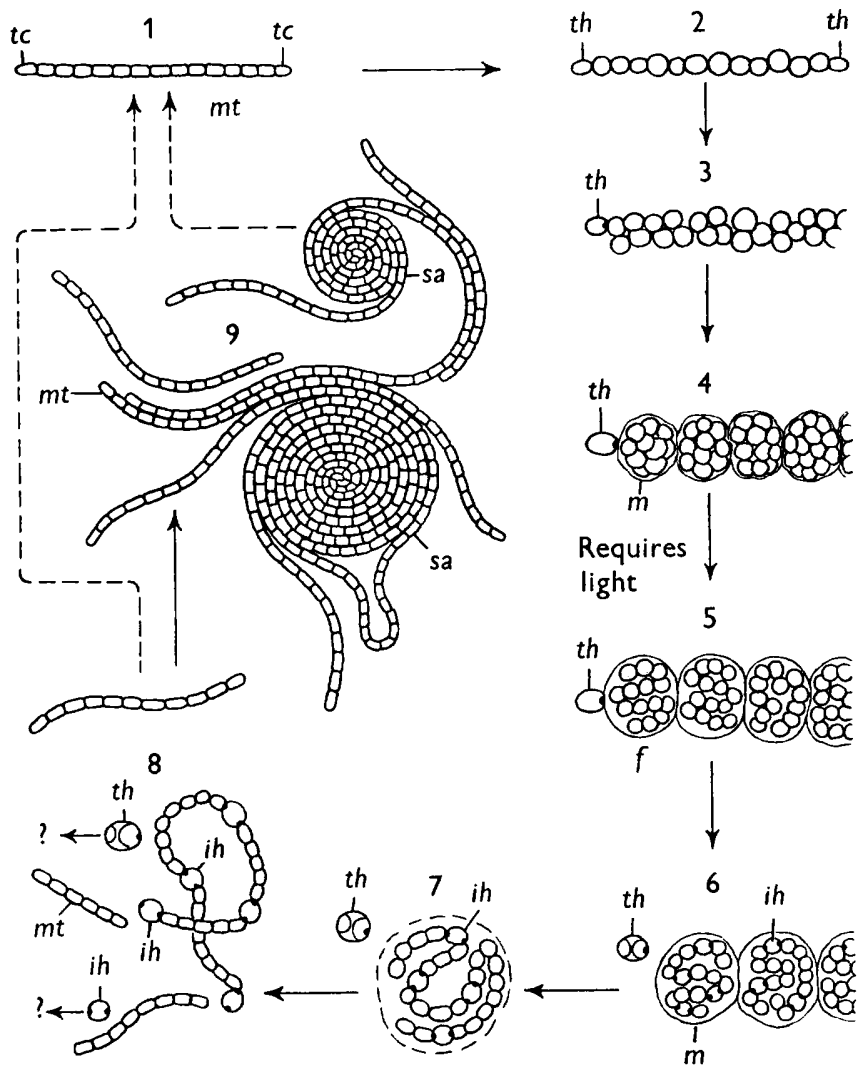

Fig. 2. A diagram of the developmental sequence indicated by arrows and numbered stages. Arrows with dotted shafts indicate that information concerning this portion of the cycle is incomplete. Stage 1 consists of the hormogone or motile trichome $(m t)$ with tapered terminal cells ' $(t c)$. In stage 2 the terminal cells begin differentiation to terminal heterocysts $(t h)$ while the intercalary cells elongate prior to division in the plane parallel to the axis of the trichome. In stages 3 and 4 division of the intercalary cells continues until a cluster of cells surrounded by a sheath or membrane $(m)$ has formed from each of the intercalary cells of the original trichome. Stage 5 is characterized by the filamentation $(f)$ of the cells within each ensheathed cluster. In stage 5 intercalary heterocysts $(i h)$ are seen in the newly formed filaments. At stage 7 the membranes enclosing each filament cluster begin to break down. During stage 8 the filaments break at the intercalary heterocysts, liberating hormogonia and heterocysts. The hormogonia swarm and may cohere in moving spiral aggregates $(s a)$ seen in stage 9 . Such hormogonia are capable of repeating the cycle of development.

with sand in $250 \mathrm{ml}$. distilled water. After grinding, the sand was separated by centrifugation and the yellow supernatant fluid sterilized by filtration through a sintered-glass bacterial filter. The addition of as little as $0.2 \mathrm{ml}$. of this extract to 
$10 \mathrm{ml}$. medium significantly stimulated growth in complete darkness. Microscopical examination indicated that the presence of the extract had enabled the organism to pass through the various developmental phases previously observed only in the light: actively motile trichomes swarmed up the sides of the tubes as evidenced by streams of hormogonia in the abundant parenchymatous growth material clinging to the tube walls. It has not yet been possible to obtain a sufficient amount of dark grown algae (aseriate stage) to prepare a suitable control extract of dark grown cells. Such an extract should be prepared in complete darkness to have a true control. Large inocula of light grown Nostoc will not become aseriate in the dark, presumably due to carry-over of some factor required for filamentation.

Although growth in the light exhibited all developmental stages regardless of whether the organism was grown under autotrophic or heterotrophic conditions, the presence of glucose exerted additional effects which were not found with sucrose. Superficially this effect was the inhibition of motile trichome formation. In cultures developing in the presence of glucose in the light, the stage of rapid seriate growth and further differentiation of heterocysts was prolonged, yielding extremely long non-motile filaments (Pl. 3, fig. 19). These filaments eventually broke at an intercalary heterocyst, but breakage occurred between the heterocyst and only one of its adjacent cells. Consequently, filaments were formed with intercalary type heterocysts in terminal positions, instead of free heterocysts which arose in the absence of glucose. The filaments so produced were capable of oscillatory motion and produced the aseriate phase of development (Pl. 3, fig. 20).

The macroscopic appearance of cultures grown in the light in media containing glucose reflected the effect of glucose on trichome development. Whereas cultures grown in inorganic media or in media containing sucrose, or fructose, in the light, were tufted and crustose, cultures grown in media containing glucose, in the light, appeared as a loose non-adherent mass of long filaments.

\section{DISCUSSION}

The observation of a sequence of morphological stages in cultures of Nostoc muscorum A suggested that a regular developmental cycle exists for this organism. The interruption of development by darkness could not be explained by a requirement of photosynthesis for growth, since the organism can maintain a slow but definite growth in the complete absence of light. Therefore, it was postulated that a factor essential for the completion of the developmental cycle was formed only in the light. In its absence $N$. muscorum $\mathbf{A}$ assumes the aseriate morphology when grown in a medium containing glucose, or may produce randomly arranged short trichomes in the presence of sucrose. Bringing the cultures into light causes a resumption of development through the regular sequence of changes observed on solid inorganic media. The light-induced development of dark-grown cultures is synchronous, allowing a detailed study of morphological changes. Not only is the light intensity required to restore development well below the minimal amount needed for photo-autotrophic growth (see Table 1), but the developmental sequence is restored when dark grown cultures are exposed to low light intensities for as little as $\mathbf{3 0} \mathrm{min}$. and then returned to complete darkness. The existence of the hypothetical substance required for development was made more likely when it was 
found that the addition of extracts prepared from Nostoc grown in the light permitted completion of the development of cultures in complete darkness, and substantially increased the rate of growth. As yet the rate of growth in darkness, in media containing extracts of light grown cells, has not equalled the rate of growth in the light.

The concept that filamentous members of the Cyanophyta exhibit developmental cycles is not new. Sauvageau (1897) believed that Nostoc punctiforme exhibited an alternation of filamentous and coccoid stages during its life cycle. Moreover, the appearance of floating colonies has prompted investigators to seek a specific mode of development which could account for the formation of these macrostructures composed of regularly oriented microscopic filaments. Usually macrocolony formation is not observed in cultures. For instance, species of Aphanizomenon and Calothrix exhibit a precise orientation of filaments within a colony when observed in nature, but a disorganized mass of filaments when cultivated in vitro. Drewes (1928) observed that hormogonia of $N$. punctiforme formed spiral aggregates on agar.

In cultures of Nostoc muscorum A, Allison et al. (1937) reported the occurrence of several morphological forms which have been described in this paper. Apparently they did not relate the occurrence of such forms with a regular cycle of development, although they did suggest that the presence of morphological variation might complicate physiological study of this organism. It is not clear from the first accounts of the Allison strain of $N$. muscorum, which apparently was isolated from soil, whether in nature this form exists in colonies. In culture, the tufted appearance of $N$. muscorum A grown in liquid inorganic media or in media containing sucrose suggests a relationship between the developmental cycle at the microscopic level and a primitive morphogenesis at the macroscopic level. The formation of hormogonia with gliding motility is certainly one link between the developmental cycle and macroscopic morphogenesis. It is known from the work of Manten (1948) that the tufts which develop in cultures of Tolypothrix are positively phototropic; however, it is not clear whether this phenomenon is linked to phototactic movements of microscopic hormogonia. The microscopic structure of the tufts formed by N. muscorum A shows a remarkable organization of the filamentous elements of this presumably primitive organism.

This work was supported by grants from the National Science Foundation and the National Institutes of Health, U.S.A. Some of the work was carried out by one of us (N.L.) in the Department of Botany, University of Wisconsin, with the support of pre-doctoral fellowships from the National Science Foundation. The advice of Drs F. K. Skoog, G. C. Gerloff and G. P. Fitzgerald is gratefully acknowledged.

\section{REFERENCES}

Aluison, F. E., Hoover, S. R. \& Morris, H. J. (1937). Physiological studies with Nostoc muscorum. Bot. Gaz. 98, 433.

Bornet, E. \& Flahault, C. (1886). Revision des nostocacées heterocystées. Ann. Sci. nat., bot. 7 ser. 3, 323.

Bornet, E. \& Thuret, G. (1880). Notes algologiques. Paris: G. Masson.

Borzi, A. (1879). Note alla morfologia e biologia delle alghe Ficocromacee. Nuovo G. bot. ital. 10, 286. 
Borzi, A. (1916). Studi sulle Mixoficee, Stigonemaceae. Nuovo G. bot. ital. N.S. 23, 559.

Brand, F. (1903). Morphologisch-physiologische Betrachtungen über Cyanophyceen. Bot. Zbl., Beihefte 15, 31.

De Bary, A. (1863). Beitrag zur Kenntnis der Nostocaceen, insbesondere der Rivularien. Flora, Jena, 46, 553.

Drewes, K. (1928). Über die Assimilation des Luftstickstoffes durch Blaualgen. Zbl. Bakt. (2. Abt.), 76, 88.

FoGG, G. E. (1942). Studies on nitrogen fixation by blue-green algae. I. Nitrogen fixation by Anabaena cylindrica Lemm. J. exp. Biol. 19, 78.

FogG, G. E. (1949). Growth and heterocyst production in Anabaena cylindrica Lemm. II. In relation to carbon and nitrogen metabolism. Ann. Bot., Lond. N.S. 13, 249.

Fremy, R. (1930). Les myxophycées de l'Afrique Equatoriale Française. Paris: Edition des archives de botanique.

Fritsch, F. E. (1904). Studies on Cyanophyceae. III. Some points in the reproduction of Anabaena. Nerw Phytol. 3, 216.

Fritsch, F. E. (1945). Structure and Reproduction of the Algae, vol. 2. Cambridge University Press.

Frirsch, F. E. (1951). The heterocyst: a botanical enigma. Proc. Linn. Soc. Lond. 162, 194.

Gertuer, L. (1921). Kleine Mitteilungen über Blaualgen. Oest. Bot. Z. 70, 158.

Geituer, L. (1925). Synoptische Darstellung der Cyanophyceen in morphologischer und systematischer Hinsicht. Bot. Zbl., Beihefte, 2. Abt, 41, 163.

HARDER, R. (1917a). Ernährungsphysiologische Untersuchungen an Cyanophyceen, hauptsächlich dem endophytischen Nostoc punctiforme. Z. Bot. 9, 145.

Harder, E. $(1917 b)$. Uber die Beziehung des Lichts zur Keimung von Cyanophyceensporen. Jb. wiss. Bot. 58, 237.

JANCZEWSKI, E. (1874). Observations sur la reproduction de quelques nostocacées. Ann. Sci. nat., 5 ser. 19, 119.

Manten, A. (1948). Phototaxis, Phototropism, and Photosyntheis in Purple Bacteria and Blue-Green Algae. Utrecht: Dissertation.

Pringsheim, E. G. (1913). Kulturversuche mit chlorophyllführenden Mikroorganismen. Beitr. Biol. Pfl. 12, 49.

Pringsheim, E. G. (1946). Pure Cultures of Algae, their Preparation and Maintenance. Cambridge University Press.

Pringsheim, E. G. (1949). A review of the relationship between bacteria and Myxophyceae. Bact. Rev. 13, 47 .

Sauvageau, C. (1897). Sur le Nostoc punctiforme. Ann. Sci. nat. 8 ser. 3, 366.

Thuret, G. (1844). Note sur le mode de reproduction du Nostoc verrucosum. Ann. sci. nat. 3 ser. 2, 319.

\section{EXPLANATION OF PLATES}

Photomicrographs of Nostoc muscorum, Allison strain, in unstained wet mounts of living material.

\section{Plate 1}

Developmental stages of Nostoc muscorum A on modified Fogg's agar, incubated at $24 \pm 2^{\circ}$ at $150 \mathrm{ft}$.-candles.

Fig. 1. Hormogonia. $\times 1200$.

Fig. 2. A hormogone in which the intercalary cells are dividing in a plane parallel to the axis of the trichome. The terminal cells are differentiating to become terminal heterocysts. $\times 1100$.

Fig. 3. Hormogonia forming the aseriate stage. $\times 1200$.

Fig. 4. New filament formation. $\times 1200$.

Fig. 5. Filament elongation and the formation of hormogonia. $\times 300$.

Fig. 6. In the presence of $1 \%$ glucose, heterocysts are elongated and the formation of hormogonia is inhibited. $\times 1500$.

Fig. 7. Streams of hormogonia migrating on the surface of agar. $\times \mathbf{1 2 5 0}$.

Fig. 8. Aggregation of hormogonia in spiral forms. $\times 250$. 


\section{Plates 2 and 3}

Morphological features of cultures grown in modified Fogg's basal medium at $24 \pm 2^{\circ}$.

Fig. 9. Filamentous morphology of $N$. muscorum A grown in illuminated cultures on basal medium. Stagnant cultures after 3 weeks of incubation at a light intensity of $200 \mathrm{ft}$.-candles. $\times 750$.

Fig. 10. Aseriate morphology of $N$. muscorum A grown in complete darkness on basal medium + glucose. The cells are arranged in packets within an enveloping sheath. Intercalary heterocysts are never seen within the packets, although they may be found on the filaments if their differentiation has already begun in the light. Stagnant culture after 6 weeks incubation in complete darkness. $\times 400$.

Fig. 11. Aseriate morphology exhibited when hormogonia produced in illuminated cultures are transferred to media containing glucose and incubated in complete darkness. By growing Nostoc muscorum $\mathbf{A}$ for 2 weeks in the light with agitation, hormogonia are formed abundantly. When inoculated into tubes containing basal medium $+1 \%(\mathrm{w} / \mathrm{v})$ glucose and incubated in complete darkness, the intercalary cells of the originally motile trichomes divide slowly to produce packets of large cells enclosed in a retaining sheath. The terminal cells do not divide but differentiate as terminal heterocysts. Intercalary heterocysts are found in such preparations as a result of differentiation which has originated in the light, since intercalary heterocysts are never found within the aseriate packets which represent the growth in the dark. Incubated for 4 weeks in the dark. $\times 700$.

Fig. 12. A preparation similar to that shown in fig. 11, but incubated in darkness for 10 weeks. The large, slowly dividing cells have continued their aseriate mode of growth. $\times 1200$.

Fig. 13. Material grown in the dark for 4 weeks, then placed in light of $150 \mathrm{ft}$.-candles for 3 days. The aseriate cells have assumed a filamentous arrangement with the production of intercalary heterocysts. The differentiation of intercalary heterocysts is coincident with filament expansion, as may be noted by comparing the relatively 'unopened' filaments at the lower right of the figure with those at the left and above. $\times 620$.

Fig. 14. A preparation similar to that shown in fig. 13. The expanding filaments, newly derived from the aseriate stage, reflect the fact that each cluster of filaments originated from one cell of the original filament. Compare with fig. 3. $\times 880$.

Fig. 15. Four weeks dark growth followed by 4 days in the light. Filament expansion and dissolution of the sheath have advanced to a point where discrete filament clusters are no longer seen. $\times 880$.

Fig. 16. Four weeks dark growth followed by 4-5 days in the light. Hormogonia begin breaking away from the intercalary heterocysts, which now have a colourless, empty appearance in contrast to their former green colour. The hormogonia are characterized by elongated cells and a distinctly tapered appearance of the terminal cells. The heterocysts often assume a shrivelled appearance, a few minutes after the hormogonia are released. $\times 880$.

Fig. 17. A preparation similar to that described under fig. 16. The filaments are seen just prior to breaking, and appear to be under tension. Breakage is actually accompanied by a sudden movement as if tension were abruptly released. $\times 750$.

Fig. 18. Four weeks dark growth followed by 5 days in the light. Such cultures consist of masses of motile hormogonia and deposited heterocysts. $\times 750$.

Fig. 19. Four weeks dark growth followed by 12 days in the light. Cultures containing glucose (but not sucrose) cease the formation of hormogonia, possibly owing to the formation of some inhibitory metabolic product. Long filaments are formed with prominent intercalary heterocysts. $\times 875$.

Fig. 20. Further development of material with the 'glucose type of morphology' mentioned above. The heterocysts elongate and often assume a flask-shaped appearance. Filament breakage at one side of the heterocyst may take place, leading to the formation of trichomes with an oscillating movement. $\times 1450$. 

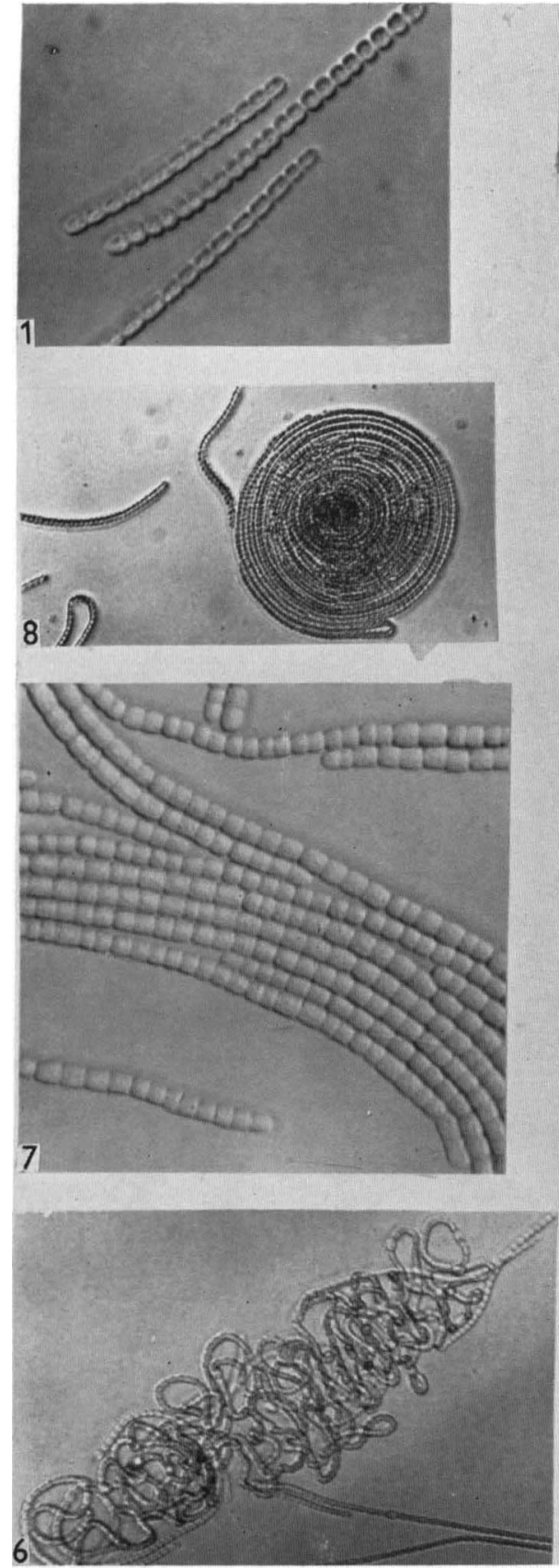
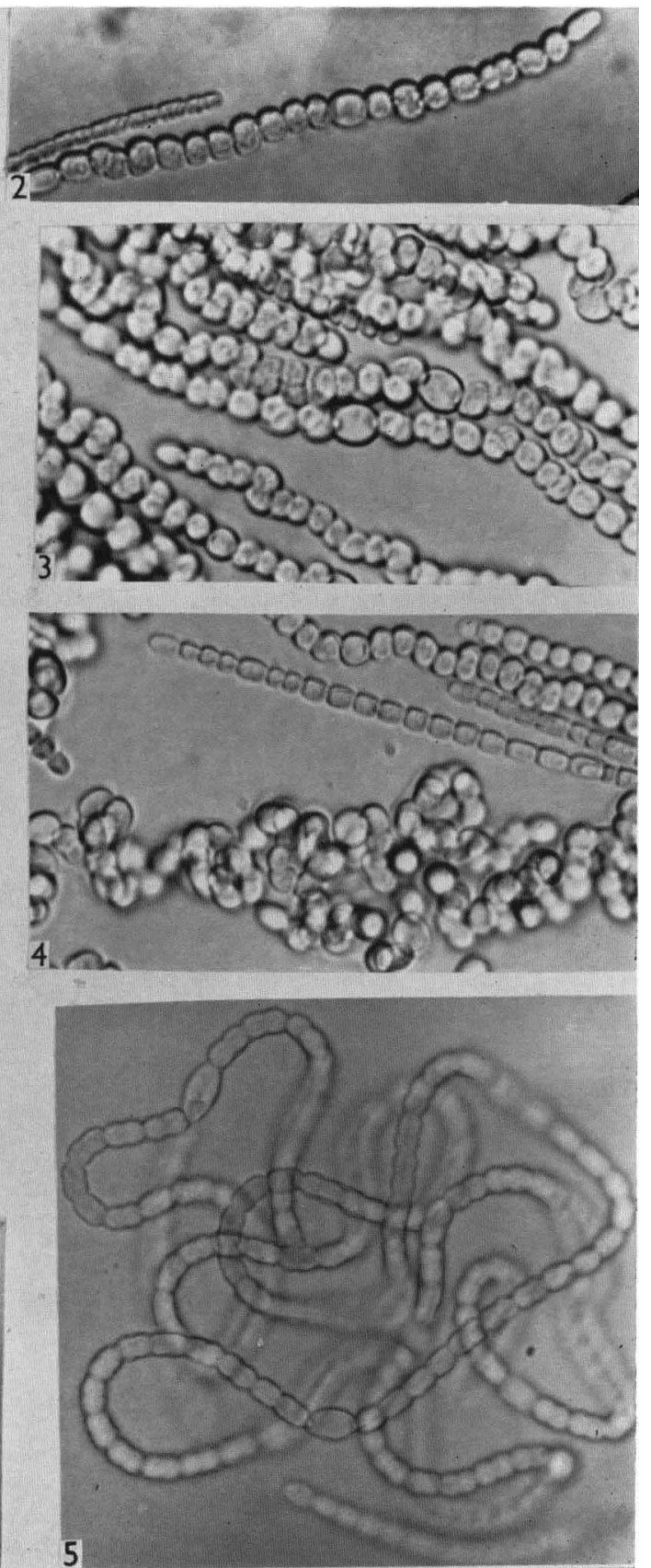


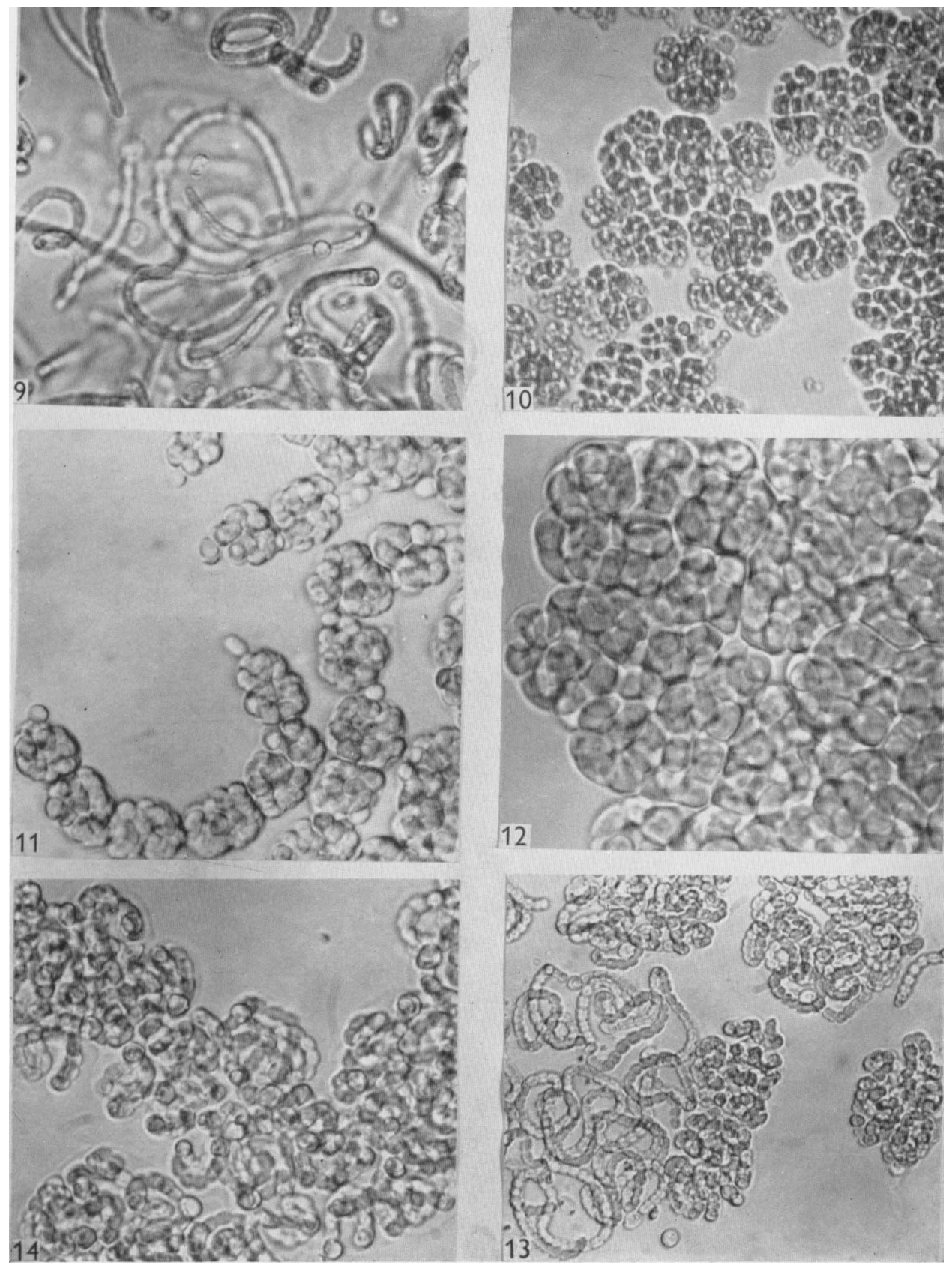




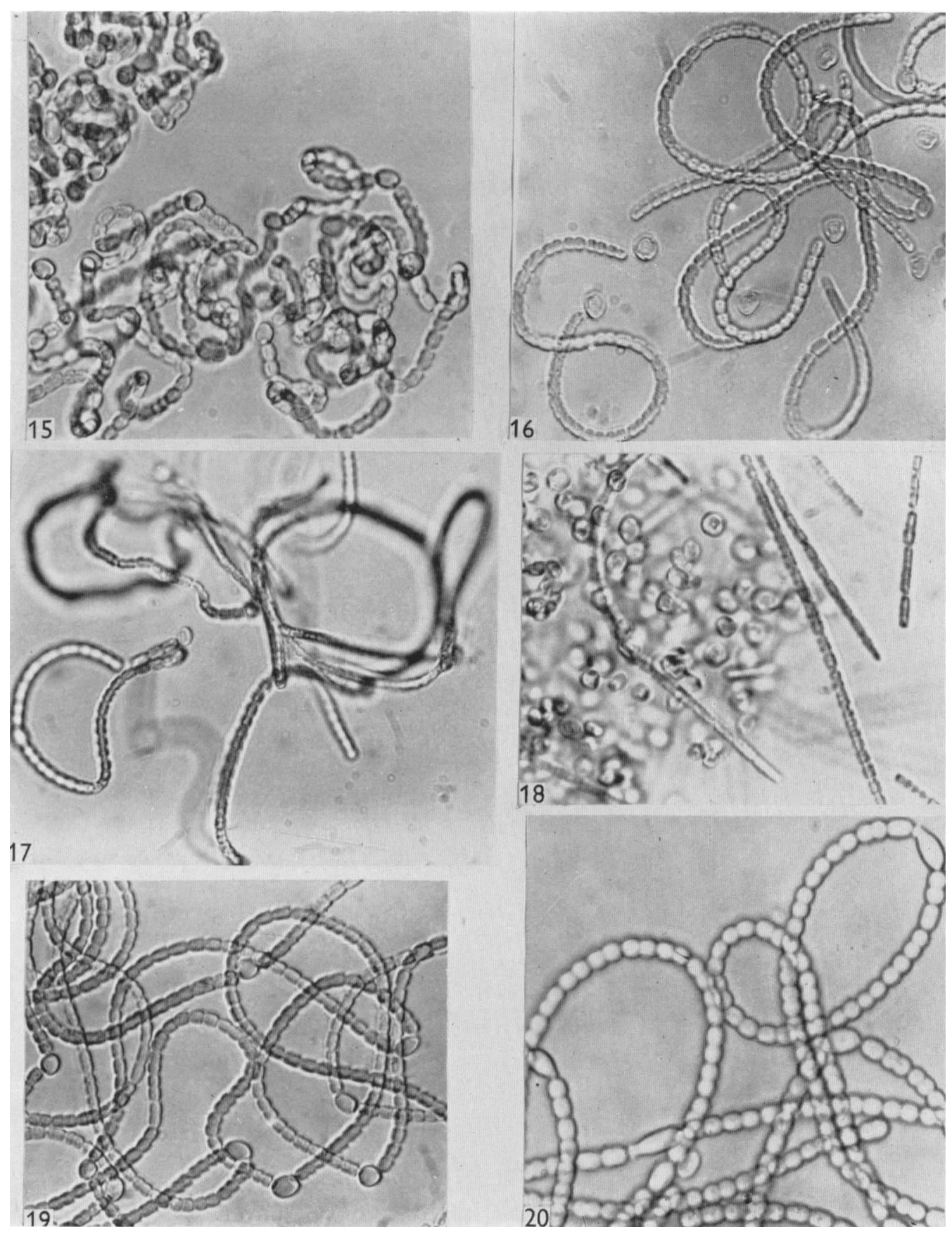

